Article

\title{
Effect of the Combination of Superabsorbent Polymers for Autogenous Shrinkage Control with Steel Fibers of High-Performance Concrete under Uniaxial Tension Using DIC
}

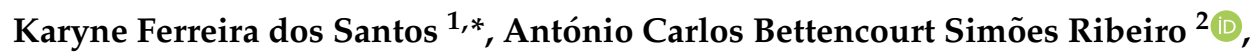 \\ Eugênia Fonseca da Silva ${ }^{1}$, Manuel Alejandro Rojas Manzano ${ }^{3}$, \\ Leila Aparecida de Castro Motta ${ }^{4}$ and Romildo Dias Toledo Filho ${ }^{5}$ (iD) \\ 1 Postgraduate Program in Structural Engineering and Construction-PECC, Department of Civil and \\ Environmental Engineering, SG-12 Building, University of Brasilia-UnB, 70910-900 Brasília-DF, Brazil; \\ eugenia@unb.br \\ 2 Materials Department, Nacional Laboratory for Civil Engineering-LNEC, Av. do Brasil 101, 1700-075 Lisbon, \\ Portugal; bribeiro@lnec.pt \\ 3 Department of Civil and Industrial Engineering, Faculty of Civil Engineering and Science, Pontifical \\ Xavierian University of Cali, Calle 18 N$^{\circ}$ 118-250, Edificio Central, 2do. Piso, Cali 760031, Colombia; \\ alejandro.rojas@javerianacali.edu.co \\ 4 Faculty of Civil Engineering-FECIV, Federal University of Uberlândia-UFU, Av. João Naves de Ávila, 2121, \\ Santa Mônica Campus 1Y, 38400-902 Uberlândia-MG, Brazil; lacastro@ufu.br \\ 5 The Alberto Luiz Coimbra Institute for Graduate Studies and Research in Engineering-COPPE, \\ Department of Civil Engineering, University of Rio de Janeiro-UFRJ, Av. Horácio Macedo 2030, \\ Ilha do Fundão, 21941-972 Rio de Janeiro, RJ, Brazil; toledo@coc.ufrj.br \\ * Correspondence: karyne.ferreira@aluno.unb.br; Tel.: +351-919282525
}

Received: 1 September 2020; Accepted: 13 October 2020; Published: 17 October 2020

check for updates

\begin{abstract}
This paper presents a study of the effect of a superabsorbent polymer (SAP) for autogenous shrinkage control on the uniaxial tensile behavior of steel fiber reinforced concrete (SFRC). The use of fibers and SAP potentially increases the durability of the concrete, preventing cracking by autogenous shrinkage and enhancing post-cracking behavior. Furthermore, SAP can provide further hydration for self-healing purposes and improve the ductility of the SFRC. In order to evaluate the effect of the addition of SAP in SFRC, dog-bone SFRC specimens with different dosages of superabsorbent polymers were cast and tested under uniaxial tension. The digital image correlation (DIC) technique was used to understand the effect of SAP on the steel fibers' crack-bridging mechanisms. Surface strains and crack openings were inferred using the DIC technique. The effect of SAP and fibers on fresh and hardened concrete was individually investigated by flow tests and compressive strength tests. Autogenous shrinkage was measured in plain concrete to investigate the minimum SAP content required to mitigate autogenous shrinkage of $0.3 \%$. The use of $0.3 \%$ SAP was also sufficient to reach multiple cracking behavior. This content of SAP completely suppressed the autogenous shrinkage with minimal side effects on compressive strength. An analytical formulation for the tensile behavior of SFRC was developed using the variable engagement model, presenting a mean correlation of $\mathrm{R}^{2}$ of 0.97 with the experimental results.
\end{abstract}

Keywords: superabsorbent polymer; steel fibers; high-performance fiber reinforced concrete; digital image correlation; autogenous shrinkage; tensile behavior 


\section{Introduction}

The present investigation focused on the tensile behavior of steel fiber reinforced concrete (SFRC) with superabsorbent polymer (SAP). In general, SAP is used to control autogenous shrinkage without significantly affecting strength and workability [1-9]. Fibers are used in concrete for cracking control [10-15].

The synergic effect of SAP and fibers has been mainly studied with synthetic fibers [16-22]. The studies of concrete with synthetic fibers and SAP shows that the presence of the two constituents modifies the tensile behavior of the composite, and improvements on the durability of the material can be achieved [23-25]. The improvements are due to the reduction in the size of the crack by increasing the number of cracks. This multi-cracking behavior is obtained not only from the presence of fibers, but also by the multi-flaws provided by SAP [16].

Studies of concrete with fibers and SAP are scarce. The study presented by [26] showed promising results on the use of SAP to densify the interfacial transition zone and reduce micro-cracks around the fibers. Wang et al. [27] conducted a splitting tensile test study with SAP and steel fiber for cellular concrete applications, although the concrete was not high strength. None of these studies were performed with concrete direct tension.

The present document intends to contribute to the understanding of the overall behavior of the composite subjected to direct tension by analyzing the crack formation and crack pattern with the digital image analysis technique, which allows for simultaneously observing the behavior of a set of fibers and flaws produced by the SAP addition, and the interaction between them. This type of behavior cannot be observed when testing only one fiber in tension [26] nor with the splitting test [27].

The investigation also deals with other specific subjects: (1) Investigate the maximum SAP content to be incorporated in high strength concrete (HSC) and steel fiber reinforced concrete (SFRC) regarding the loss of compressive strength and workability; (2) Investigate a minimum SAP content that controls the autogenous shrinkage of HSC; (3) Characterize the tensile properties of SFRC with different SAP contents and complement the regular analysis with the crack pattern with full-field strain measurement using DIC; and (4) Develop an analytical model for predicting the tension behavior of HSC with varying SAP dosage.

\section{Materials and Methods}

\subsection{Materials}

Portland cement of high initial strength conforming to [28] Type CPV-ARI (CIPLAN, Brasília, Brazil) was used for all mixes in this study. A silica fume, of the non-densified type, meeting the requirements of the standard [29] was supplied by the national company Silmix (Breu Branco, Pará, Brazilcountry). The physical and chemical properties of the cement and silica fume are shown in Table 1. Locally available sand of the Corúmba River, with the maximum size of $4.75 \mathrm{~mm}$ and gradation conforming to [30] standard usable zones, was used. The sand fineness module was 2.73, and the specific mass was $2.65 \mathrm{~kg} / \mathrm{dm}^{3}$. A water reducer of high-efficiency, superplasticizer ADVA CAST 129 from Grace Company (Sorocaba, São Paulo, Brazil), based on polycarboxylates, was used to maintain the fluidity of the mortar within a fixed range for all mixes.

Table 1. Basic chemical composition of cement and silica fume.

\begin{tabular}{ccc}
\hline Component & Cement (\%) & Silica Fume (\%) \\
\hline $\mathrm{SiO}_{2}$ & 24.41 & 93.95 \\
$\mathrm{Al}_{2} \mathrm{O}_{3}$ & 7.09 & 0.16 \\
$\mathrm{CaO}$ & 53.74 & 0.74 \\
$\mathrm{Fe}_{2} \mathrm{O}_{3}$ & 3.02 & 0.27 \\
$\mathrm{MgO}$ & 4.36 & 0.86 \\
$\mathrm{SO}_{3}$ & 3.28 & - \\
$\mathrm{Na}_{2} \mathrm{O}$ & 0.28 & 0.37 \\
$\mathrm{~K}_{2} \mathrm{O}$ & 0.77 & 0.84 \\
Density $\left(\mathrm{g} / \mathrm{cm}^{3}\right)$ & 3.03 & 2.21 \\
\hline
\end{tabular}




\subsubsection{Steel Fibers}

Steel fibers of DRAMIX OL 13/.16 mm from BEKAERT (Zwevegem, Belgium), illustrated in Figure 1, with the content of $1.28 \%$ in volume, were used. These were made of smooth steel of $13 \mathrm{~mm}$ in length, $0.16 \mathrm{~mm}$ in nominal diameter, aspect ratio of 81.25 , Young's modulus of $200 \mathrm{GPa}$, and tensile strength of $2750 \mathrm{MPa}$.

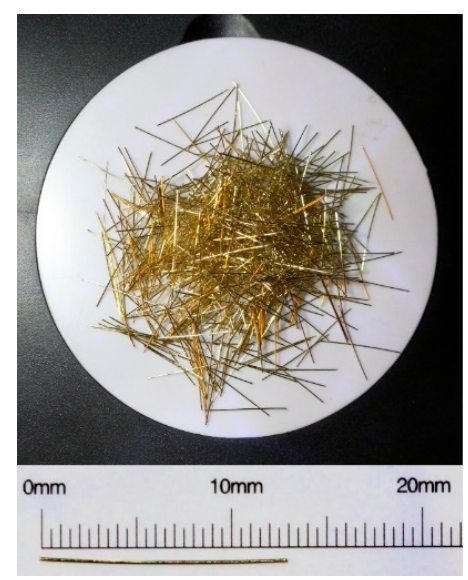

Figure 1. Dramix Ol 13/.16 steel fiber from Bekaert Company.

\subsubsection{Superabsorbent Polymers (SAP)}

The superabsorbent polymer used was an acrylic acid/acrylamide (Technical University of Denmark, Lyngby, Denmark) with covalent cross-links produced by the reverse suspension polymerization technique, with a mean particle size $\left(D_{50}\right)$ of $66.3 \mu \mathrm{m}$. It has an absorption in the cementitious medium of $18 \mathrm{~g}$ of water for $1 \mathrm{~g}$ of SAP, and the density of $1.456 \mathrm{~g} / \mathrm{cm}^{3}$. The particle size curve of the SAP characterized by the portion of particles with diameters smaller than $27.3 \mu \mathrm{m}$ is $10 \%\left(\mathrm{D}_{10}\right)$, and the portion of particles with diameters below $101.7 \mu \mathrm{m}$ is $90 \%$. $\left(\mathrm{D}_{90}\right)$. It was developed for particular use in a high alkaline environment such as the cement suspension. It was supplied by Prof. Ole Mejlhede Jensen and developed at the Technical University of Denmark (DTU). In Figure 2, the polymer is presented in the dry and swollen state by using the scanning electron microscope and digital microscope H1000X/ S1000X, respectively.

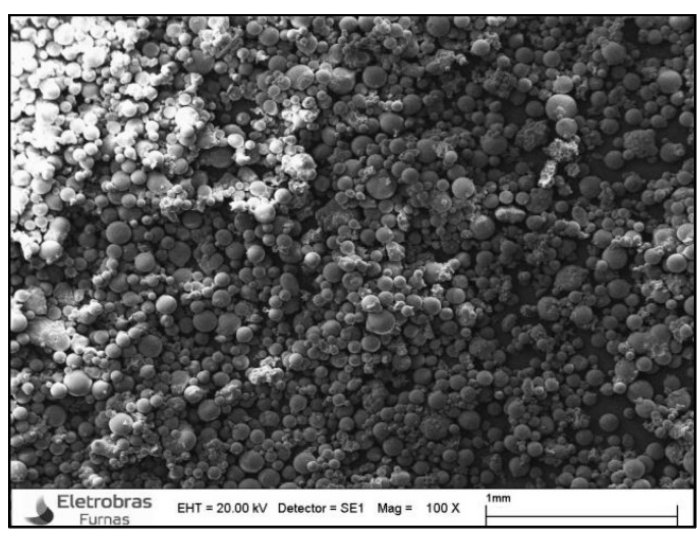

(a)

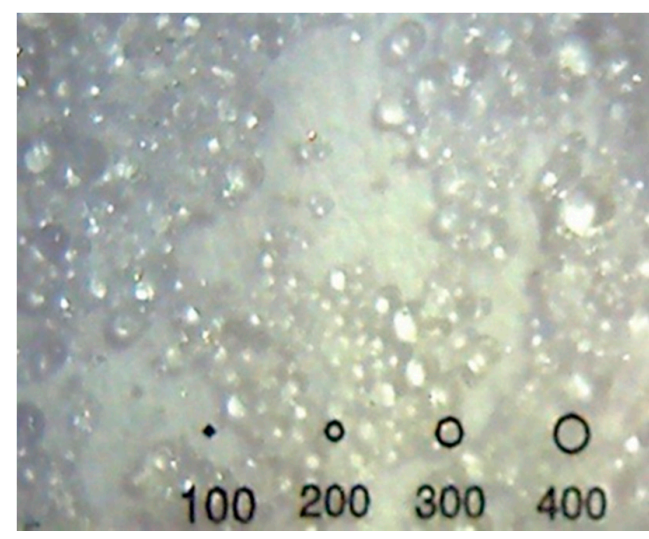

(b)

Figure 2. Superabsorbent polymer: (a) dry; (b) swollen. The spheres have a diameter in micrometers.

The water absorption capacity of SAP was measured by the slump flow consistency method and by means of graduated cylinders proposed by [31]. Absorption of SAP was tested for deionized water 
and cement filtrate since the absorption of the mixing water by the SAP takes place with the addition of water to the remaining components of the concrete mix, in a way that the activation of SAP takes place in a highly active electrochemical environment. The absorption capacity in deionized water was $96 \mathrm{~g}$ of water per $1 \mathrm{~g}$ of SAP.

The smaller absorption of cement filtrate, when compared to absorption of water, caused by calcium and magnesium ions present in the cementitious fluid (increase the cross-linking in SAP) [32,33], is an advantage for self-healing purposes. This effect leads to a smaller void creation in the hardened mortar and, after crack formation, when the SAP gets into contact with clean water, it will have swollen larger and temporarily seal the crack. The saturated environment can then provoke self-healing of the crack by hydration of the anhydrous cement under certain conditions and quantities of SAP.

\subsubsection{Mix Proportions}

In order to investigate the combined effect of the SAP and steel fibers, eight concrete mixtures were prepared according to Table 2. These included three reference compositions, two without SAP or fibers (REF-035 and REF-040), and another with fibers and without SAP (REF-035F). The remaining five mixtures included SAP or SAP and fibers.

Table 2. Composition of the concrete mixtures, values in $\mathrm{kg} / \mathrm{m}^{3}$.

\begin{tabular}{|c|c|c|c|c|c|c|c|c|c|}
\hline Mixture $\left(\mathrm{kg} / \mathrm{m}^{3}\right)$ & Cement & Silica & Sand & SAP & Fiber & Superplasticizer & $w / c_{\text {(basic) }}$ & $\mathrm{w} / \mathrm{c}_{\text {(total) }} 1$ & Flow (mm) \\
\hline REF-040 & 654.2 & 65.4 & 1264.5 & 0 & 0 & 8.50 & 0.40 & 0.40 & 200 \\
\hline SAP- 0.2 & 675.8 & 67.6 & 1306.5 & 1.35 & 0 & 12.50 & 0.35 & 0.38 & 183 \\
\hline REF-035F & 675.8 & 67.6 & 1306.5 & 0 & 100 & 13.50 & 0.35 & 0.35 & 307 \\
\hline SAP-0.2F & 675.8 & 67.6 & 1306.5 & 1.35 & 100 & 13.50 & 0.35 & 0.38 & 243 \\
\hline SAP-0.3F & 675.8 & 67.6 & 1306.5 & 2.03 & 100 & 13.50 & 0.35 & 0.40 & 230 \\
\hline
\end{tabular}

${ }^{1}$ Including water absorbed by SAP.

All mixtures presented low $\mathrm{w} / \mathrm{c}$ ratio and high strength. The total water-cement $(\mathrm{w} / \mathrm{c})$ ratio was set at 0.35 or water-binder of 0.32 . A reference mixture with w/c of 0.4 was also prepared for comparison with the mixture where additional water was placed due to SAP. In the mixtures without fibers, the content of the superplasticizer was adjusted in order to reach the required workability.

The mortar compositions all had the same proportions of binder and aggregate and the content of SAP varied from 0 to $0.6 \%$. In the mixtures with fibers, the amount of superplasticizer was fixed at $2 \%$ and the fibers content was set constant at $1.28 \%$ in volume.

The mortars were prepared in a mechanical mixer (Solotest São Paulo, Brazil) under the following steps. The first step was dry mixing the cement, the SAP, and the sand for $5 \mathrm{~min}$ at a slow speed. The second step was the water and superplasticizer addition for $2 \mathrm{~min}$, and then mixing at a high speed for $5 \mathrm{~min}$. Then, the mixer was stopped, the edges of the bowl were scraped, and followed by mixing for another $3 \mathrm{~min}$ at high speed. In the correspondent mixtures, the fibers were then added constantly in motion for $5 \mathrm{~min}$ at slow speed, preventing the ball bearing effect, then the edges were scraped again for $3 \mathrm{~min}$. Finally, the mortar was mixed for $5 \mathrm{~min}$ at high speed to ensure a uniform consistency. For proper compaction, the mixes were cast into molds placed on a vibrating table. The specimens were moved to a room with $100 \%$ relative humidity and $22 \pm 1{ }^{\circ} \mathrm{C}$. They were demolded after $24 \mathrm{~h}$ and continued in this room until the testing date.

\subsection{Experimental Program}

\subsubsection{Measurement of Flowability and Compressive Strength}

Slump flow tests were carried out right after mixing, following the procedure [34]. The fresh mortar was poured into a Hagerman cone (larger base diameter of $100 \mathrm{~mm}$, height of $60 \mathrm{~mm}$, and a smaller base of $70 \mathrm{~mm}$ ) into two layers. Each layer was tamped 10 times evenly distributed, and then 
the cone was gently removed, and the spread was measured. The largest diameter was measured along with the diameter in the perpendicular direction.

Compressive tests were carried out according to the standard [35]. Cylinder specimens ( $\varnothing 50 \mathrm{~mm}$ $\times \mathrm{L} 100 \mathrm{~mm}$ ) were used, and an average of three tested samples was reported. The base of the specimens was ground to ensure a smooth and plane surface. The test adopted a Microcomputer-controlled electromechanical universal test systems (MTS), and the loading rate was $0.5 \mathrm{~mm} / \mathrm{min}$.

\subsubsection{Autogenous Shrinkage}

The autogenous shrinkage was assessed according to the methodology developed by [36], which is a modified method of [37] using the [38] apparatus, shown in Figure 3. The test consists of the measurement of the deformation of mortars, cast in a prismatic mold with nominal dimensions of $7.5 \times 7.5 \times 28.5 \mathrm{~cm}$. Each mold was previously prepared, with polystyrene layers inside to decrease friction, allowing the concrete to move freely. Additionally, two threaded metal pins were placed in the extremities of the mold aligned with the specimen's longitudinal axis. Strain gauges are couples in these pins and connected to a computer to collect and store the data. The distance between these pins is called G, and the measurement of this distance determines the shrinkage.

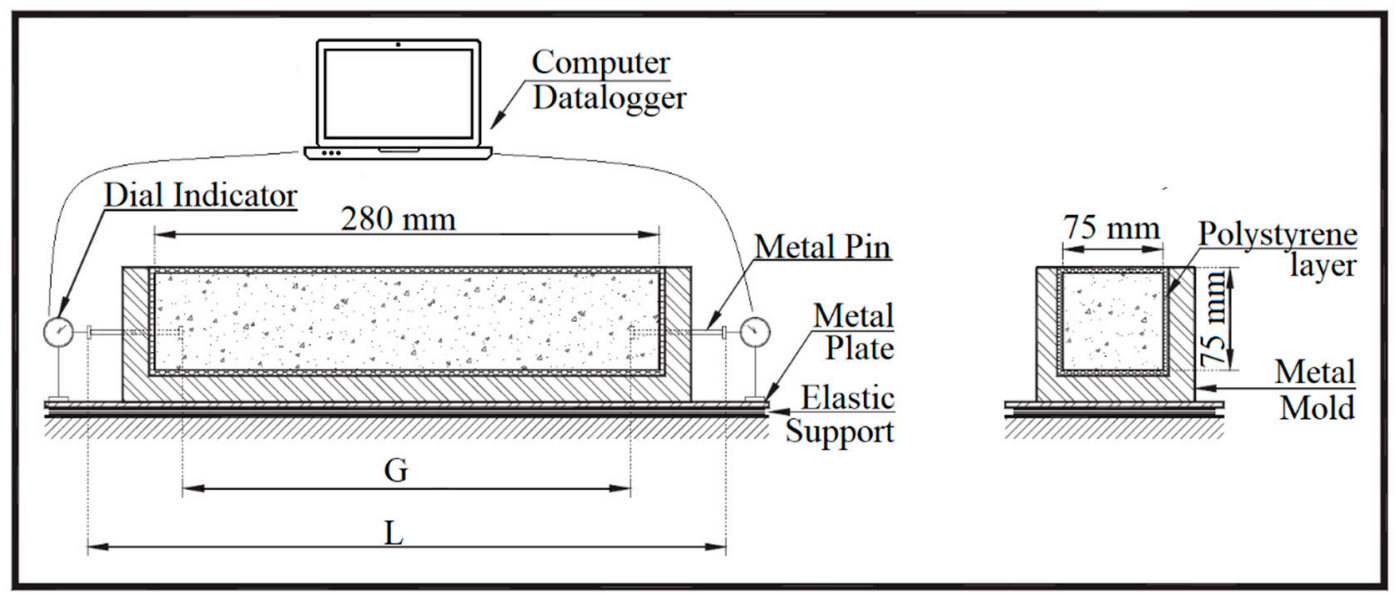

(a)

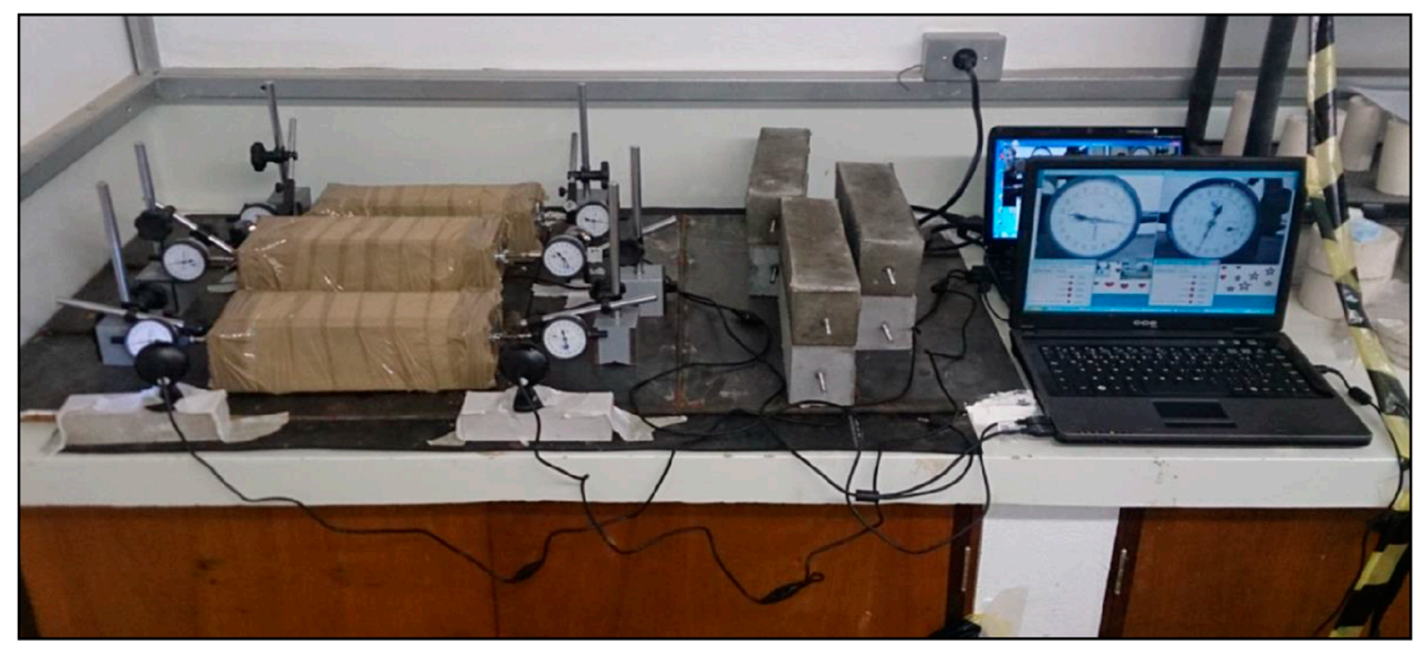

(b)

Figure 3. Autogenous shrinkage test: (a) test setup scheme and (b) on going test.

After casting, to prevent the loss of water to evaporation, the mold with the mortar was wrapped with multiple layers of polystyrene and adhesive tape. The weight of the mold with mortar was 
measured, and they were stored in a chamber with $50 \pm 2 \%$ of humidity and $21 \pm 2{ }^{\circ} \mathrm{C}$ for 28 days, where the straingauges continuously recorded the $\mathrm{G}$ distance.

\subsubsection{Uni-Axial Testing Equipment with Digital Image Correlation (DIC) Arrangement}

In order to verify the strain-hardening behavior of all HPC mixtures at 28 days, a series of direct tensile tests were performed following [39]. An INSTRON (Instron, São José dos Pinhais, Paraná, Brazil) electronic universal testing machine with displacement control and load capacity of $100 \mathrm{kN}$ was used at a constant speed of $0.3 \mathrm{~mm} / \mathrm{min}$. The loading force was measured on a computerized data recording system as for the strain was measured by two linear variable displacement transducers (LVDT, HBM, São Paulo, Brazil), placed on both sides of the specimen. Additionally, the strain was also measured by digital image correlation (DIC, Correlated Solutions, Irmo, United States of America). The tensile setup and geometry of the specimen are shown in Figure 4.

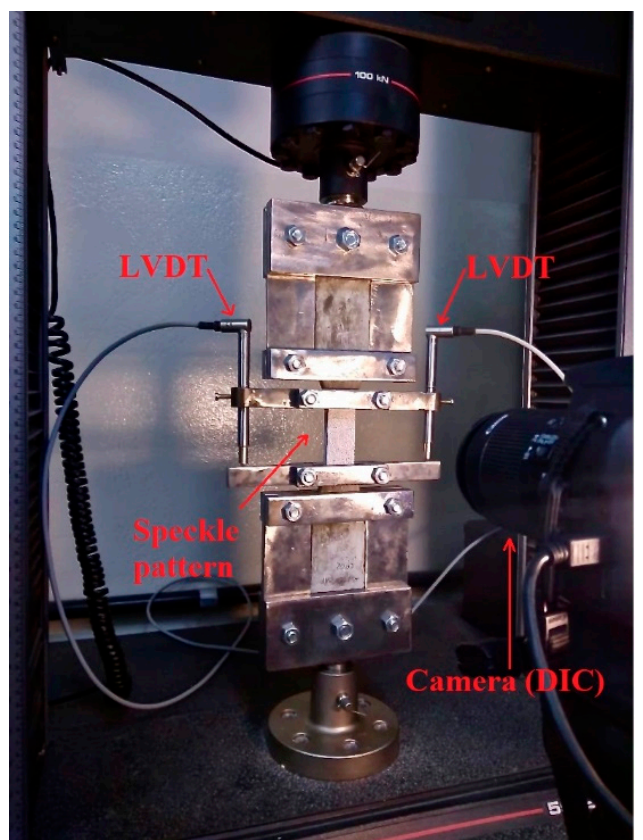

(a)

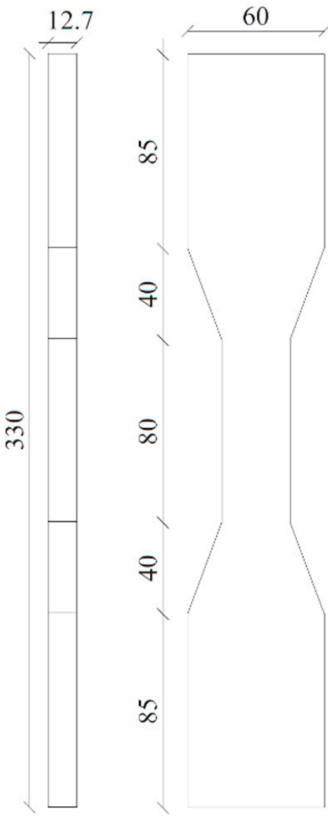

(b)

Figure 4. The direct uniaxial tensile test: (a) test setup with DIC and (b) specimen dimension (mm).

The DIC was used to analyze the crack pattern and the continuous deformation of the specimen concerning the applied load to assist the investigation of the strain hardening behavior with the addition of the SAP and steel fibers. The DIC setup included a digital camera, sufficient light in the specimen, and the sample preparation. The sample preparation consisted of painting the specimen with white paint and aleatory and heterogeneously painting dark dots to form distinct patterns that can be recognized by the image correlation program. For the program to work well, these dots, the camera configuration, and position were adjusted for each dot to have four to six pixels in the picture. Before the test began, a calibration image was taken for each test to convert the pixel scale to a millimeter scale. The camera, testing machine, and LVDT were all started simultaneously so that the data could be correlated later on.

Image processing software VIC-2D was used in this study to correlate different images and the corresponding deformations. The software relates the deformed images by dividing the area of interest (AOI) into many small regions, called subsets, where each subset is unique and identified by the program via the dots pattern. The program detects the change in the first image subset, set as a reference, with the images taken during the test and calculates the distance, which is used to calculate the full-field displacement and strains by interactive techniques [40]. 
Due to the brittle behavior, it is not possible to obtain the strain-stress curve of plain concrete specimens with the direct tension test with displacement control. In this case, the splitting tensile strength test was carried out based on [41]. This method was used mainly to evaluate the effect of SAP incorporation on tensile strength. Three cylindrical samples $(\varnothing 100 \mathrm{~m} \times 200 \mathrm{~mm})$ were used to measure the splitting tensile strength of concrete on the seventh and 28th day. The machine for testing the splitting tensile strength was a MTS microcomputer-controlled electromechanical universal test systems, with the loading speed of $0.2 \mathrm{MPa} / \mathrm{s}$.

\section{Results and Discussions}

\subsection{Influence on Mortar Flow}

The flow values of each mix and the corresponding superplasticizer content are presented in Table 2. The results of mixture REF-35 and SAP-02, without fibers, showed that to keep the same flow $(183 \mathrm{~mm})$ in both mixtures, $0.2 \%$ of SAP required an increase of $12 \%$ in the superplasticizer dosage. Mixture SAP-0.3, with the same superplasticizer dosage but another $0.1 \%$ of SAP, led to a reduction in the flow $(180 \mathrm{~mm})$. This effect on flow is expected, as the increase of SAP content also increased the particle concentration, but the effect was limited and manageable. Paiva [42] proposed that a water-reducing agent could be efficient at maintaining the flowability since SAP particles do not interfere with the plasticizer chains.

The adverse effects of steel fibers on the workability of concrete have been widely discussed by [43], and reinforced by recent publications with high strength concrete such as [44,45]. In order to have good workability after the incorporation of fibers, the superplasticizer content was increased to $2 \%$ of the cement weight, which led to a reference flow of $307 \mathrm{~mm}$ (REF-035F).

The effect of SAP on the flow can be more clearly seen in the last four mixtures of Table 2, since the water content and the superplasticizer dosage were kept constant. The flow progressively decreases as the addition of SAP increases. The reduction was $20.85 \%, 25.1 \%$, and $32.2 \%$ for $0.2 \%, 0.3 \%$, and $0.6 \%$ of SAP, respectively.

The decrease in the workability suggests that the additional water provided to fill the SAP is actually being absorbed by the SAP, and the flow decrease is due to lesser free water per unit of volume. Some extra water absorption by the SAP may also be occurring, these findings were supported by [46]. The opposite effect was reported by [47-49], which leads to a gap in the literature as the effect of the SAP in the workability is not entirely understood. The authors in $[4,31,50]$ explained that the broad diversification of results would depend on the methodology used to accurately estimate the amount of water absorbed by SAP in the cementitious environment. The over or underestimated amount of additional water can affect the workability and the total w/c. Another hypothesis of the loss of workability was provided by [51], who believed that the swollen SAP particles behaved as soft aggregates and offered a restraining effect in the rheology of the mortar. Nevertheless, all the mixtures maintained good workability and no signs of segregation.

\subsection{Compressive Strength}

A summary of the compressive strength results for the fiber reinforced concrete and the plain concrete at 28 days is provided in Figure 5 and Table 3. Each compressive strength result is the average of six specimens.

Increases in SAP dosage for the same $\mathrm{w} / \mathrm{c}_{\text {(basic) }}$ tended to almost linearly decrease the compressive strength for both mixture series (with and without fiber reinforcement). However, comparing the compressive strength of mixtures with same $\mathrm{w} / \mathrm{c}_{\text {(total })}, \mathrm{REF}-040$, and SAP-0.3, the values were similar. This indicates the major role of the total volume of pores on strength, regardless of the presence or absence of SAP.

Strictly speaking, in order to individually evaluate the influence of the SAP, a specific reference mixture should be manufactured containing the same total $\mathrm{w} / \mathrm{c}$ ratio, but for the purposes of the present work, this information was not considered necessary. 


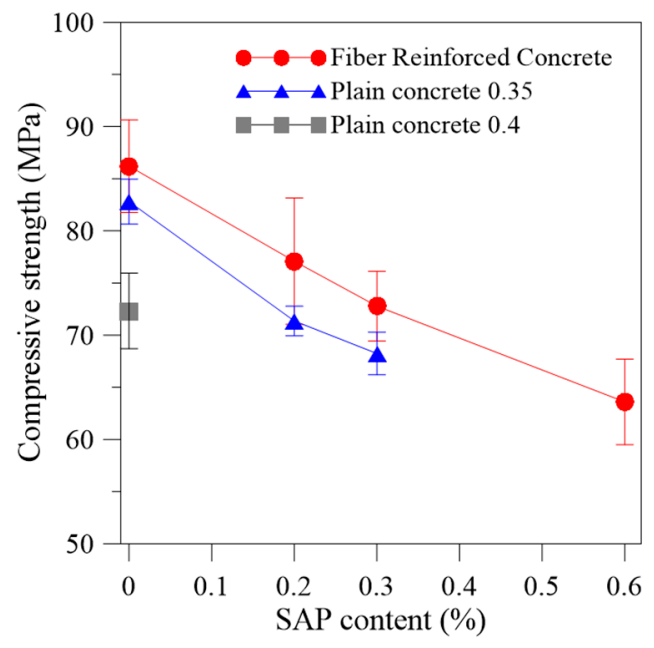

Figure 5. Compressive strength results at 28 days of the fiber reinforced concrete of the $\mathrm{w} / \mathrm{c}_{(\text {basic) }}$ of 0.35 ; plain concrete without fiber reinforcement with the $\mathrm{w} / \mathrm{c}_{(\text {basic) }}$ of 0.35 , and the plain concrete without fiber reinforcement with the $\mathrm{w} / \mathrm{c}_{\text {(basic) }}$ of 0.40 .

Table 3. Mechanical properties of the high strength concrete and steel fiber reinforced concrete.

\begin{tabular}{|c|c|c|c|c|}
\hline Mixture & $\begin{array}{l}\text { Mean Compressive } \\
\text { Strength (MPa) }\end{array}$ & $\begin{array}{c}\text { Strength Reduction } \\
\text { Considering the } w / \mathrm{c}_{(\text {basic })}(\%)\end{array}$ & $\begin{array}{l}\text { Mean Tensile Stress } \\
\text { (MPa-First Cracking }\end{array}$ & $\begin{array}{l}\text { Ratio of Tensile to } \\
\text { Compressive Strength }\end{array}$ \\
\hline REF-035 & $82.80 \pm 2.1$ & - & 5.39 & 0.065 \\
\hline SAP-0.2 & $71.36 \pm 1.4$ & 13.82 & 5.04 & 0.071 \\
\hline SAP-0.3 & $68.24 \pm 2.0$ & 17.58 & 5.07 & 0.074 \\
\hline REF-035F & $86.20 \pm 4.4$ & - & $6.01 \pm 0.45$ & 0.070 \\
\hline SAP-0.6F & $63.60 \pm 4.1$ & 26.22 & $3.23 \pm 0.23$ & 0.051 \\
\hline
\end{tabular}

This subject leads to a discussion presented in the literature that has yet to be enlightened. Many authors have reported the loss of compressive strength in the literature. However, as published by [50], this loss of strength could be provoked by the excess of water addition due to a misleading measure of the SAP absorption in the cementitious environment. Simple methods have been used to estimate the SAP absorption capacity and could be overestimating the water of absorption, increasing the water in the mixture, and lowering the compressive strength. However, this hypothesis was not validated by the slump results obtained in this research. If there were an excess of water in the fresh state, the slump would not decrease since it would facilitate the workability.

Another explanation and more common for the loss of strength, supported by [4,51-53], and others, determined that the initial swelling of SAP creates a reasonable amount of macropores due to the SAP swelling. Snoeck et al. [51] further explained that in the fresh mix, macropores spontaneously form and become occupied by swollen SAP particles. Following this, the concrete pore solution is consumed by cement hydration, which decreases the ambient moisture where the SAP is located. Afterward, SAP slowly releases the inside water, causing the SAP to shrink. After SAP voids form, they result in increases in the total porosity of the concrete system. However, some studies have reported a straight gain due to effective internal curing, where the later hydration of the cement provided by the SAP entrapped water densified the pore structure, which was not the case in this study.

The addition of steel fibers in the mixture increased the compressive strength in $4.11 \%, 8.03 \%$, and $5.51 \%$ when compared with the reference without fiber reinforcement and $\mathrm{w} / \mathrm{c}_{\text {(basic) }}$ of 0.35 for the $0.2 \%$, $0.3 \%$, and $0.6 \%$ of SAP incorporation, respectively. The $0.6 \%$ of SAP was determined to be the highest SAP incorporation for this mix design. Given that, according to [54,55], the lower limit of strength to be classified as HSC is $55 \mathrm{MPa}$, for this research, it was stipulated to reach a minimum value of $60 \mathrm{MPa}$ so that the concrete can be classified as high strength. 


\subsection{Autogenous Shrinkage}

The deformation measured in the test was considered as autogenous shrinkage since minimum moisture exchange occurred between the specimens and environment due to the coat of aluminum and plastic tape applied to the specimens before starting the test.

The scope of the research was to find the content of SAP that could mitigate or control autogenous shrinkage. Therefore, the worst-case scenario was to carry out the test without fiber reinforcement. The autogenous shrinkage for the mixtures without fiber reinforcement up to 28 days are shown in Figure 6. Each value represents an average of three specimens. As displaced in Figure 6, the reference, REF-035, presented autogenous shrinkage much higher than that of ordinary concrete, and increased significantly in the first seven days due to the absence of coarse aggregate and low water/binder ratio. REF-035 presented a maximum deformation of $424 \mu \mathrm{m} / \mathrm{m}$ and an initial expansion of $106 \mu \mathrm{m} / \mathrm{m}$, which was overcome by autogenous shrinkage after $10 \mathrm{~h}$.

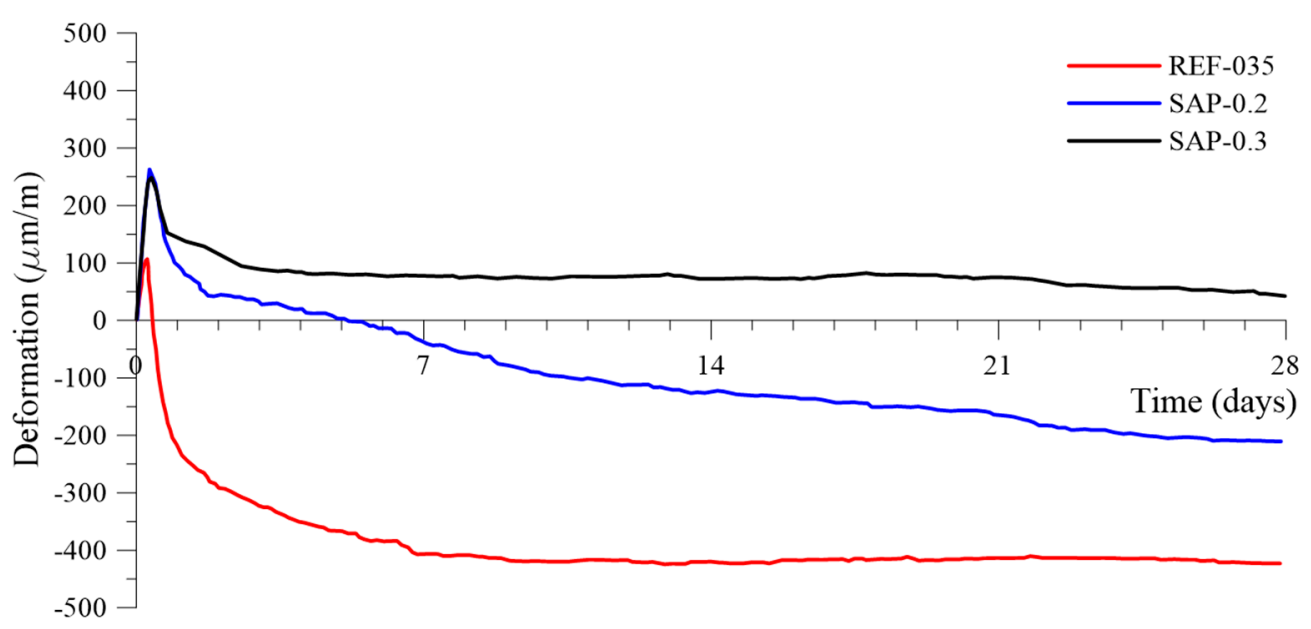

Figure 6. Autogenous strain $(\mathrm{um} / \mathrm{m})$ for cement mortar mixtures without fibers $\mathrm{w} / \mathrm{c}_{\text {(total) }}$ of 0.35 , with SAP additions of $0.2 \%$ and $0.3 \%$, determined from time zero up to 28 days.

The general trends of the curves in Figure 6 tended to be stable after 10 days. When studying the SAP-containing mixtures, the percentage of $0.3 \%$ completely mitigated the autogenous shrinkage and presented a maximum expansion of $248 \mu \mathrm{m} / \mathrm{m}$ at six hours after setting. The shrinkage did not counterbalance the expansion and, after 28 days, still presented $42 \mu \mathrm{m} / \mathrm{m}$ of expansion. The expansion phenomenon is not yet fully understood, but there are several attempts at explanation, for example, involving expansive pressure by forming hydration products (the high $\mathrm{MgO}$ content of the cement used may be a source of early expansion). This can be beneficial for some prestressed applications since the concrete compressive strength is higher than its tensile strength. The material is likely to withstand the maximum compression efforts induced by the expansion. Additionally, this expansion can be helpful and contribute to preventing cracking from drying shrinkage.

The content of $0.2 \%$ of SAP addition reduced $90 \%$ of the autogenous shrinkage compared to the reference at the age of seven days and reduced $50 \%$ at 28 days. It also presented an expansion of $262 \mu \mathrm{m} / \mathrm{m}$ at four hours after time 0 . The authors in $[1,2,56]$ described the water releasing mechanism of the SAP after setting of the cement-based material, which explained the reduction of autogenous shrinkage. The incorporation of SAP leads to the formation of controlled water-filled microscope inclusions, which prevent internal moisture evaporation from compensating water loss for curing, promote the hydration of unhydrated cement, and reduce the autogenous shrinkage.

The use of more than $0.3 \%$ of SAP addition is considered to ensure autogenous shrinkage control, with beneficial properties such as the expansion, which can avoid cracking and produce a more durable concrete, as seen in [57]. 


\subsection{Tensile Properties}

For the unreinforced specimens, the splitting tensile test was performed, and the tensile strength with the ratio of tensile to compressive strength for all mixtures is presented in Table 3. The specimens failed as expected, releasing almost all the energy soon after the peak load. The average tensile strength of the specimens without fiber reinforcement was $5.11 \pm 0.2 \mathrm{MPa}$.

Typical stress-strain/load-displacement curves of the developed SFRC with SAP particles at 28 days are presented in Figure 7a. A diagrammatic sketch of the strain-softening behavior presented by [10] is shown in Figure $7 \mathrm{~b}$, who classified the composites based on their tensile response. The parameters regarding Naaman (2006), chosen to characterize the tensile behavior and to implement the analytical model described in the next section, were: first structural cracking stress $\left(\sigma_{\mathrm{cc}}\right)$ and force $\left(\mathrm{F}_{\mathrm{cc}}\right)$; first structural cracking strain $\left(\varepsilon_{\mathrm{cc}}\right)$ and displacement $\left(\mathrm{d}_{\mathrm{cc}}\right)$; maximum post-cracking stress $\left(\sigma_{\mathrm{pc}}\right)$ and force $\left(\mathrm{F}_{\mathrm{pc}}\right)$; crack opening $\left(\mathrm{w}_{\mathrm{pc}}\right)$; and tension toughness index $(\mathrm{TTI})$, as presented in Table 4. Before the crack opening, the acquired displacement was calculated as a strain of the composite; after the first crack, it was evaluated as a crack opening.

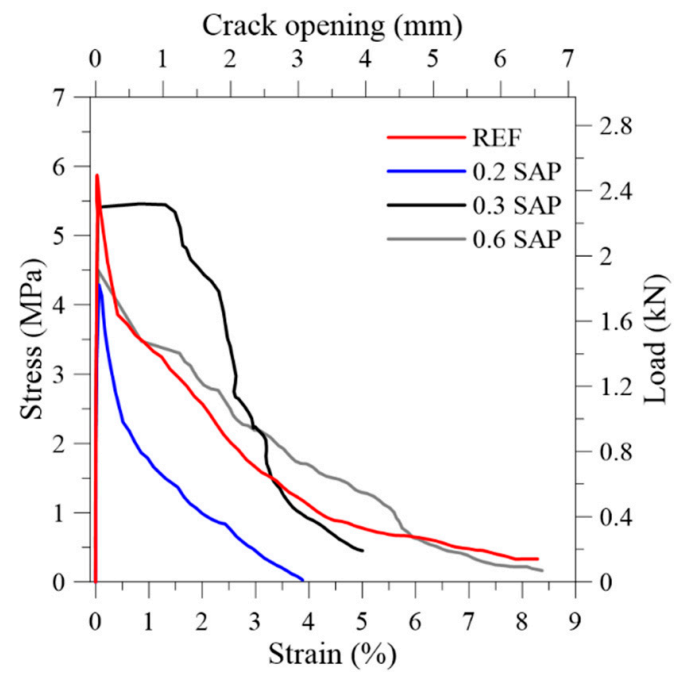

(a)

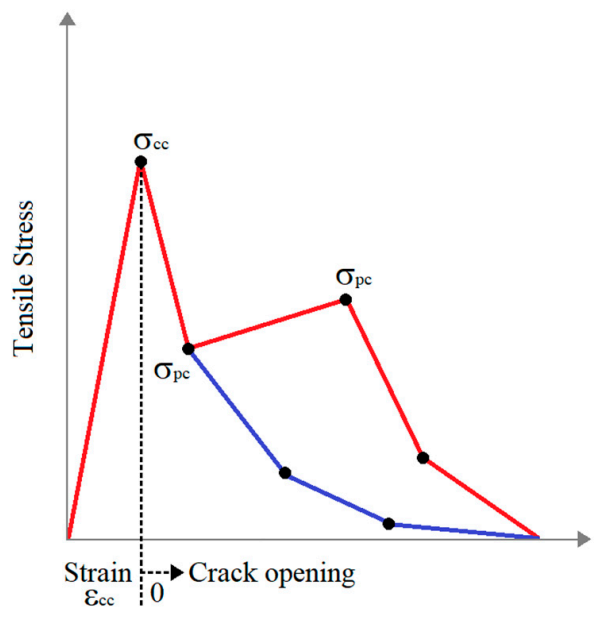

(b)

Figure 7. Stress $x$ strain curve of: (a) SFRC with varying SAP content; (b) typical curves of strain softening behavior.

Table 4. Tensile properties of SFRC specimens at 28 days.

\begin{tabular}{lcccccccc}
\hline Mixture & $\begin{array}{c}\mathbf{F}_{\mathbf{c c}} \\
(\mathbf{k N})\end{array}$ & $\begin{array}{c}\mathbf{F}_{\mathbf{p c}} \\
(\mathbf{k N})\end{array}$ & $\begin{array}{c}\sigma_{\mathbf{c c}} \\
(\mathbf{M P a})\end{array}$ & $\begin{array}{c}\sigma_{\mathbf{p c}} \\
(\mathbf{M P a})\end{array}$ & $\begin{array}{c}\mathbf{d}_{\mathrm{cc}} \\
(\mathbf{m m})\end{array}$ & $\begin{array}{c}\varepsilon_{\mathrm{cc}} \\
(\mathbf{\%})\end{array}$ & $\begin{array}{c}\mathbf{w}_{\mathbf{p c}} \\
(\mathbf{m m})\end{array}$ & $\begin{array}{c}\text { TTI } \\
(\mathbf{M P a})\end{array}$ \\
\hline REF-035F & 2.45 & 1.63 & 5.87 & 3.86 & 0.023 & 0.029 & 0.325 & 0.1336 \\
SAP-0.2F & 1.85 & 0.99 & 4.29 & 2.31 & 0.050 & 0.064 & 0.404 & 0.0491 \\
SAP-0.3F & 2.38 & 2.26 & 5.62 & 5.35 & 0.035 & 0.044 & 1.169 & 0.1623 \\
SAP-0.6F & 1.92 & 1.41 & 4.50 & 3.31 & 0.038 & 0.048 & 1.235 & 0.1491 \\
\hline
\end{tabular}

The main aspect to be witnessed by the SAP incorporation was the increase in the ductility of the composite. This behavior could be better observed by the DIC analysis shown in Figure 8 as the crack pattern of the SFRC. According to [10], the higher the strength, the lower the strain at the peak stress. This phenomenon could be observed in this experiment. Therefore, the general trade-off that exists in most materials between strength and ductility also applies to the developed composites. The tension toughness index (TTI) is a measurement of toughness calculated by area under the stress $\times$ strain curve until the specimen ultimately failed. In general, higher tension toughness (or energy absorption) was tightly related to higher SAP content, except for the SAP-0.2F. Compared to the reference, the TTI for SFRC increased by $21 \%$ for SAP-03F, $12 \%$ for SAP-06F, and decreased $37 \%$ for SAP-02F. 


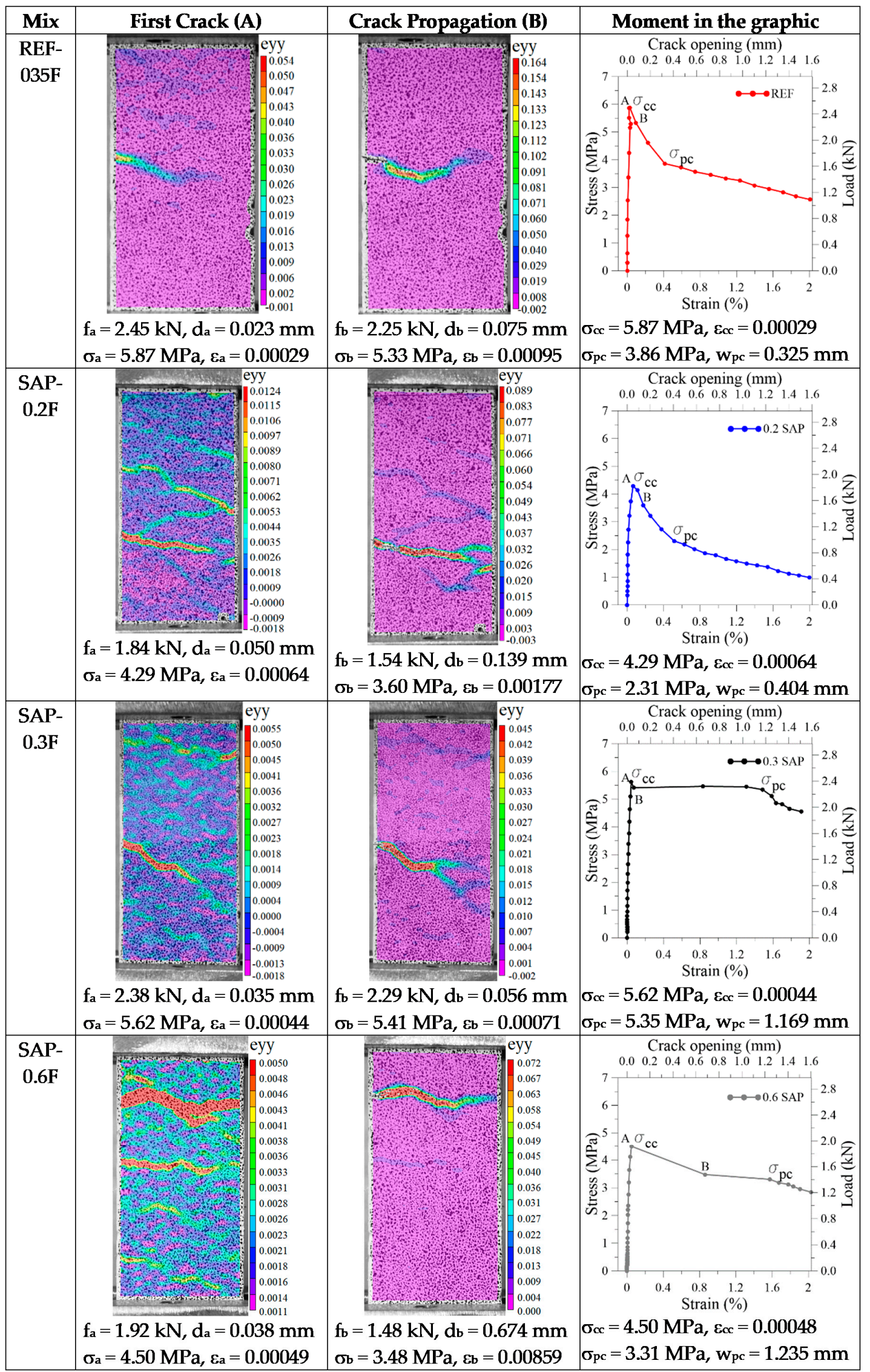

Figure 8. Morphology of cracking apparent on the face of a specimen of SFRC, where A is the first cracking point, and B is the crack propagation, both presented in the respective graphic for each mix. 
From Figure 8, the images of the DIC in the first cracking point were named A. The point soon after the cracking occurrence was named $\mathrm{B}$. These points were correlated between the camera and the data acquisition. It was possible to observe that at the first cracking stress $\left(\sigma_{\mathrm{cc}}\right)$, point $\mathrm{A}$, the composite without SAP produced one transverse localized crack and propagated later on at point $B$. As for the composites with SAP, they produced a different damage mode, leading to the creation of several cracks in the first peak stress $\left(\sigma_{\mathrm{cc}}\right)$. Moreover, when the stress concentration opens a single crack, the cracking evolution, shown in point $B$, produces a different morphology with more branches, releasing more energy and in accordance with the TTI results.

The authors in [16] incorporated SAP to control and improve the performance of fiber-reinforced concrete with polyvinyl alcohol (PVA) fibers. SAP improved the ductility of the material by the insertion of a mechanical flaw. According to the micromechanical theory developed by [24,25], one of the criteria to increase the toughness and multiple cracking in the cementitious composite is when $\sigma_{\mathrm{cc}}$ $\leq \sigma_{\mathrm{pc}}$. This criterion can be achieved by decreasing the strength of the matrix by inserting a flaw in the matrix. The matrix tensile strength equals the stress of the bond between the fiber and matrix, and the composite develops a more ductile behavior.

This behavior was intensely studied with PVA fibers. However, for steel fibers, it was observed that as soon as the specimen cracked on reaching the $\sigma_{\mathrm{cc}}$, there was a sudden drop in stress resistance, leading to extensive cracking, widening before the stresses were transferred from the matrix to the fibers $\left(\sigma_{\mathrm{pc}}\right)$. Nevertheless, it was also noted from Figure 8 that the SAP incorporation enhanced the toughness of the composite as it increased the multiple-crack behavior when the difference of $\sigma_{\mathrm{cc}}$ and $\sigma_{\mathrm{pc}}$ was lower. The $0.3 \% \mathrm{SAP}$ addition achieved the best behavior because the regain of strength after the first cracking was significant. The difference between the two stresses was 0.3 MPa. However, for the developed SFRC, the $\sigma_{\mathrm{pc}}$ was not higher than the $\sigma_{\mathrm{cc}}$, and the multiple-cracking behavior was not achieved. Still, the fibers fulfilled their purpose to increase the toughness and produce a progressive, yet gradual decrease in the load-carrying capacity.

The overall trend of the tensile strength presented a decrease as the SAP addition increased. The mixture with a content of $0.2 \%$ SAP was the exception. Despite following the general tendency to decrease the tensile strength by the insertion of SAP, it presented, in both cases of the concrete with and without fiber reinforcement, a higher reduction than the ones with more SAP insertion. This behavior was not expected and no reasonable explanation was found since, for the results of compressive strength and slump, it was inside the pattern of decrease. As for the autogenous shrinkage, it also presented results inside the expected trend.

Liu, Farzadnia and Shi [27] along with Wang et al. [26], are the few articles investigating the tensile behavior of steel fiber reinforced concrete with superabsorbent polymers. Wang et al. [27] focused on investigating different steel fibers types and contents with an established SAP content in the mixture, as opposed to our research that fixed the fiber type and content to investigate the influence of different SAP additions.

As reported by [26], the addition of SAP increased the flexural to compressive strength ratio of their ultra-high performance concrete (UHPC). For the UHPC with small size SAP, the increase in the ratio regarding the reference was $8 \%$ with $0.3 \%$ of SAP and $22 \%$ with $0.6 \%$ of SAP. Despite the difference in the tensile measurement, flexural strength is an indirect measure of the tensile strength. This phenomenon could also be observed for the concrete without fiber reinforcement (Table 3). The ratio increased by $9 \%$ for the addition of $0.2 \%$ SAP and $14 \%$ for the increase with $0.3 \%$. The increment in the tensile to compressive strength ratio means that the SAP's internal cure is more beneficial for the development of tensile than compressive strength. Liu, Farzadnia and Shi [26] raised the hypothesis that the addition of SAP increased the interstitial bonding strength of steel fibers. Additionally, this could be one of the critical factors in increasing the tensile to compressive results. However, for SFRC, only the $0.3 \%$ of SAP addition showed an improvement in the ratio of $16 \%$; as for the other content, no improvement was observed. 
Analytical Tensile Evaluation of SAP Incorporation

There are many analytical models to describe the behavior of fiber reinforced concrete, especially regarding steel fiber reinforcement, for example, [58-60]. It was not within the scope of this work to evaluate the best analytical model to describe the experimental obtained curves. Instead, a more contemporary and consolidated model was chosen to describe and predict the SFRC. The variable engagement model (VEM) has been extensively used to investigate fiber reinforcement, even in DIC analyses of direct tensile test such as in [61], more details of the model can be found in [62,63]. This model gives an approach for modeling strain softening behavior on uniaxial tension, where the fibers are randomly orientated in three dimensions.

For modeling the developed SFRC, the fibers were straight, so the mechanical anchorage was dismissed for the model. The total tensile stress developed by the model was composed by the sum of the stress of the matrix and the stress provided by the frictional bond between fiber and matrix, as exemplified in Figure 9a and Equation (1).

$$
f_{t}=f_{c t}+f_{s t}
$$

where $f_{t}$ is the total tension stress carried by the fiber reinforced concrete; $f_{c t}$ is the stress carried by the matrix; and $f_{s t}$ is the stress carried by the fiber.

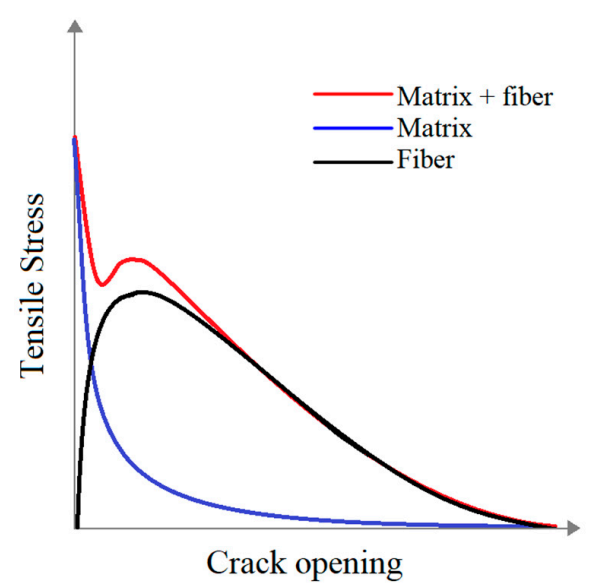

(a)

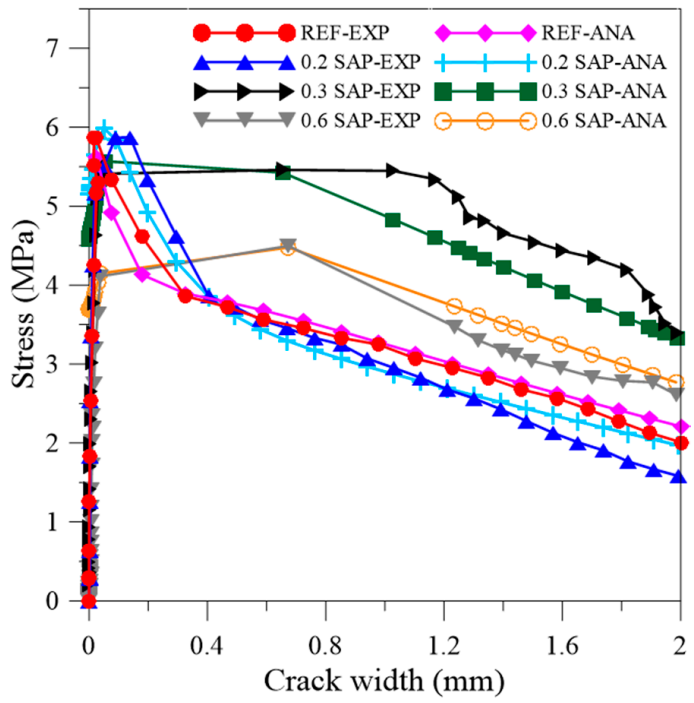

(b)

Figure 9. (a) Typical stress versus crack opening after cracking for the fiber-matrix composite. (b) Analytical model with experimental results for the SFRC with SAP additions.

VEM considers that the embedded fiber is pulled out from the crack's side with the shorter embedded fiber length, and ignores the axial elastic deformation of the fibers. An exponential tension softening relationship is provided as:

$$
f_{c t}=f_{t}^{\prime} \cdot \exp (-c \cdot w)
$$

where $f^{\prime}{ }_{t}$ is the tensile strength of the specimens without fibers; $w$ is the crack width of the specimen at a given load; and $c$ is an attenuation factor for the concrete matrix undergoing tension decay after cracking. The $c$ parameter was a variable to the model fitting into the experimental curves.

The stress carried by the fiber is given by:

$$
f_{s t}=K_{f} \alpha_{f} \rho_{f} \tau_{b}
$$


where $K_{f}$ is the global orientation factor; $\alpha_{f}$ is the aspect ratio; $\rho_{f}$ is the volumetric ratio; and $\tau_{b}$ is the mean shear stress between the fiber and the matrix.

The aspect ratio is given by:

$$
\alpha_{f}=\frac{l_{f}}{d_{f}}
$$

where $l_{f}$ is the length of the fiber and $d_{f}$ the diameter, and the global orientation factor is given by:

$$
K_{f}=\frac{\left(\tan ^{-1}(w / \alpha)\right)}{\pi}\left(1-\frac{2 w}{l_{f}}\right)^{2}
$$

where $\alpha$ is the engagement parameter, which for fiber composites with straight or end hooked steel fibers is of $\alpha=d_{f} / 3.5$.

For the model to work without the fiber fracture, the following equation must be satisfied. For the present case, it was fulfilled, and the model without fiber fracture was chosen. Additionally, by observing the cracked section after the tensile test was performed, no fiber fracture was observed.

$$
l_{f}<l_{c}=\frac{d_{f}}{2} \frac{\sigma_{f u}}{\tau_{b}}
$$

where $l_{c}$ is the critical fiber length and $\sigma_{f u}$ is the ultimate tensile strength of the fiber.

The analytical model presented using Equations (1)-(6) was plotted with the experimental results in Figure 9b, where EXP designates the experimental and ANA represents the analytical curves.

Since the composites presented the same fiber content and type, in order for the model to fit the experimental results, only three parameters could vary: the parameter $\mathrm{c}$ that is dependent of the type of concrete; the stress of the fiber bond; and the tensile stress of each composite at 28 days. The tensile stress was provided by the results obtained. The other parameters were initially based on the literature and then modified to adjust the model to the experimental curves better.

The fitting of these parameters revealed that the bond between the fiber and matrix was enhanced with the SAP addition, except for the $0.2 \%$ as already discussed, to eventually be an out layer. The initial value set for the bond strength was $10 \mathrm{MPa}$, tested by [64]. The interpolation to better fit the experimental curve to the model presented the following results: for the reference, the stress bond was $9 \mathrm{MPa}$, and SAP-0.2F, SAP-0.3F, and SAP-0.6F were 8, 13.5, and $11.2 \mathrm{MPa}$, respectively. This confirmed that SAP-0.3F presented a superior bond between the fiber and matrix, consequently enhancing the toughness and presenting the best behavior. Furthermore, SAP-0.6F validated that the SAP addition enhanced the bond between the matrix and steel fiber.

The parameter c can be physically interpreted as the behavior of the concrete or mortar undergoing tension decay after cracking; the typical value of concrete is 15 and 30 for mortar. Furthermore, the interpolation revealed that the SAP addition modified the matrix to be more likely to be a mortar than concrete. The REF-035 was 15 as a result of the fitting, which is the typical value of concrete. The addition of $0.2,0.3$, and 0.6 presented the values of 6,18 , and 22 , respectively.

Overall, the proposed models presented a good correlation, indicated by a mean correlation $\mathrm{R}^{2}$ of 0.97. Future work to investigate the pull-out behavior and confirm the indicated values should be performed. Furthermore, the analytical model can describe the behavior of the SFRC with SAP and can be applied in the future analysis of elements under uniaxial tension.

\section{Conclusions}

This study established the framework to investigate the tension behavior of a durable steel fiber reinforced concrete with increasing dosage of SAP and to develop a HSC with SAP to mitigate autogenous shrinkage and develop an analytical model for predicting the tension behavior of HSC with varying SAP dosage. Based on the results presented, the following conclusions can be drawn: 
- HSC can incorporate a dosage of $0.6 \%$ of SAP, keeping high strength and workability.

- Autogenous shrinkage can be adequately mitigated with the content of $0.3 \%$ of SAP. However, a content of $0.2 \%$ may give sufficient reduction to avoid cracking.

- The content of $0.3 \%$ of SAP was shown to be beneficial in different aspects. It successfully mitigated autogenous shrinkage, can be used without major influence on workability, is compatible with high compressive strength, and significantly enhanced the SFRC's ductile performance.

- The variable engagement model used was capable of describing the behavior of the SFRC with SAP. Moreover, it can be used in future finite element applications.

Author Contributions: Conceptualization, K.F.d.S., A.C.B.S.R., and E.F.d.S.; Methodology and Data Acquisition, K.F.d.S., M.A.R.M., and L.A.d.C.M.; Supervision, A.C.B.S.R. and E.F.d.S.; Writing-Original Draft Preparation, K.F.d.S., A.C.B.S.R. and E.F.d.S.; Writing-Review \& Editing, K.F.d.S., A.C.B.S.R., E.F.d.S., and R.D.T.F. All authors have read and agreed to the published version of the manuscript.

Funding: This study was financed in part by the Coordenação de Aperfeiçoamento de Pessoal de Nível Superior-Brasil (CAPES)-Finance Code 001.

Acknowledgments: The authors gratefully acknowledge the financial support given by CAPES to the execution of the present research project.

Conflicts of Interest: The authors declare no conflict of interest.

\section{References}

1. Jensen, O.M.; Hansen, P.F. Water-entrained cement-based materials:I. Principles and theoretical background. Cem. Concr. Res. 2001, 31, 647-654. [CrossRef]

2. Jensen, O.M.; Hansen, P.F. Water-entrained cement-based materials: II. Experimental observations. Cem. Concr. Res. 2002, 32, 973-978. [CrossRef]

3. Schröfl, C.; Mechtcherine, V.; Gorges, M. Relation between the molecular structure and the efficiency of superabsorbent polymers (SAP) as concrete admixture to mitigate autogenous shrinkage. Cem. Concr. Res. 2012, 42, 865-873. [CrossRef]

4. Hasholt, M.T.; Jensen, O.M.; Kovler, K.; Zhutovsky, S. Can superabsorent polymers mitigate autogenous shrinkage of internally cured concrete without compromising the strength? Constr. Build. Mater. 2012, 31, 226-230. [CrossRef]

5. Mechtcherine, V.; Reinhardt, H. Application of Super Absorbent Polymers (SAP) in Concrete Construction: State-of-the-Art Report Prepared by Technical Committee 225-SAP, 1st ed.; Mechtcherine, V., Reinhardt, H., Eds.; Springer: Dordrecht, The Netherlands, 2012; ISBN 978-94-007-2733-5.

6. Mechtcherine, V.; Gorges, M.; Schroefl, C.; Assmann, A.; Brameshuber, W.; Ribeiro, A.B.; Cusson, D.; Custódio, J.; Da Silva, E.F.; Ichimiya, K.; et al. Effect of internal curing by using superabsorbent polymers (SAP) on autogenous shrinkage and other properties of a high-performance fine-grained concrete: Results of a RILEM round-robin test. Mater. Struct. Constr. 2014, 47, 541-562. [CrossRef]

7. Shen, D.; Wang, X.; Cheng, D.; Zhang, J.; Jiang, G. Effect of internal curing with super absorbent polymers on autogenous shrinkage of concrete at early age. Constr. Build. Mater. 2016, 106, 512-522. [CrossRef]

8. Wyrzykowski, M.; Igarashi, S.I.; Lura, P.; Mechtcherine, V. Recommendation of RILEM TC 260-RSC: Using superabsorbent polymers (SAP) to mitigate autogenous shrinkage. Mater. Struct. Constr. 2018, 51, 1-7. [CrossRef]

9. Reis, P.F.O.; Evangelista, F.; Silva, E.F. Profile of internal relative humidity and depth of drying in cementitious materials containing superabsorbent polymer and nano-silica particles. Constr. Build. Mater. 2020, 237, 117412. [CrossRef]

10. Naaman, A.E.; Reinhardt, H.W. Proposed classification of HPFRC composites based on their tensile response. Mater. Struct. Constr. 2006, 39, 547-555. [CrossRef]

11. Kwon, S.; Nishiwaki, T.; Mihashi, H. Self-healing Capability of Ultra-High-Performance Fiber-Reinforced Concrete (UHP-FRC). In Proceedings of the Fifth International Conference on Self-Healing Materials, Durham, NC, USA, 22-24 June 2015.

12. Van Zijl, G.P.A.G.; Wittmann, F.H.; Oh, B.H.; Kabele, P.; Toledo Filho, R.D.; Fairbairn, E.M.R.; Slowik, V.; Ogawa, A.; Hoshiro, H.; Mechtcherine, V.; et al. Durability of strain-hardening cement-based composites (SHCC). Mater. Struct. Constr. 2012, 45, 1447-1463. [CrossRef] 
13. Afroughsabet, V.; Biolzi, L.; Ozbakkaloglu, T. High-Performance Fiber-Reinforced Concrete: A Review. J. Mater. Sci. 2016, 51, 6517-6551. [CrossRef]

14. Naaman, A.E. Fiber reinforced concrete: Five decades of progress. In Proceedings of the 4th Brazilian Conference on Composite Materials, io de Janeiro, Brazil, 22-25 July 2018; pp. 35-56.

15. Di Prisco, M.; Plizzari, G.; Vandewalle, L. Fibre reinforced concrete: New design perspectives. Mater. Struct. Constr. 2009, 42, 1261-1281. [CrossRef]

16. Yao, Y.; Zhu, Y.; Yang, Y. Incorporation superabsorbent polymer (SAP) particles as controlling pre-existing flaws to improve the performance of engineered cementitious composites (ECC). Constr. Build. Mater. 2012, 28, 139-145. [CrossRef]

17. Snoeck, D.; Van Tittelboom, K.; Steuperaert, S.; Dubruel, P.; De Belie, N. Self-healing cementitious materials by the combination of microfibres and superabsorbent polymers. J. Intell. Mater. Syst. Struct. 2014, 25, $13-24$. [CrossRef]

18. Tosun-Felekoğlu, K.; Felekoğlu, B.; Ranade, R.; Lee, B.Y.; Li, V.C. The role of flaw size and fiber distribution on tensile ductility of PVA-ECC. Compos. Part B Eng. 2014, 56, 536-545. [CrossRef]

19. Snoeck, D.; De Belie, N. Effect of fibre type and superabsorbent polymers on the self-healing properties of strain-hardening cementitious materials. In Proceedings of the 11th International Symposium on Brittle Matrix Composites (BMC), Warsaw, Poland, 28-30 September 2015; pp. 213-222.

20. Sherir, M.A.A.; Hossain, K.M.A.; Lachemi, M. Interaction of Superabsorbent Polymers and Admixtures on the Properties of Engineered Cementitious Composites. Can. Soc. Civ. Eng. 2015, 1, 191-200.

21. Snoeck, D. Self-Healing and Microstructure of Cementitious Materials with Microfibres and Superabsorbent Polymers. Ph.D. Thesis, Ghent University, Ghent, Belgium, 15 December 2015.

22. Mignon, A.; Snoeck, D.; Dubruel, P.; Van Vlierberghe, S.; De Belie, N. Crack Mitigation in Concrete: Superabsorbent Polymers as Key to Success? Materials 2017, 10, 237. [CrossRef]

23. Li, V.C. On Engineered Cementitious Composites (ECC) A Review of the Material and Its Applications. J. Adv. Concr. Technol. 2003, 1, 215-230. [CrossRef]

24. Wang, S.; Li, V.C. Tailoring of pre-existing flaws in ECC matrix for saturated strain hardening. Fract. Mech. Concr. Struct. 2004, 8, 1005-1012.

25. Li, V.C.; Wang, S.; Wu, C. Tensile strain-hardening behavior of polyvinyl alcohol engineered cementitious composite (PVA-ECC). ACI Mater. J. Am. Concr. Inst. 2001, 98, 483-492.

26. Liu, J.; Farzadnia, N.; Shi, C. Effects of superabsorbent polymer on interfacial transition zone and mechanical properties of ultra-high performance concrete. Constr. Build. Mater. 2020, 231, 117142. [CrossRef]

27. Wang, X.; Zhang, S.; Wang, C.; Cao, K.; Wei, P.; Wang, J. Effect of steel fibers on the compressive and splitting-tensile behaviors of cellular concrete with millimeter-size pores. Constr. Build. Mater. 2019, 221, 60-73. [CrossRef]

28. ABNT NBR 16697. Cimento Portland—Requisitos; Brazilian Association of Technical Standards: São Paulo, Brazil, 2018; p. 9.

29. ABNT NBR 13956. Sílica Ativa Para uso com Cimento Portland em Concreto, Argamassa e Pasta Parte 1: Requisitos; Brazilian Association of Technical Standards: São Paulo, Brazil, 2012; p. 6.

30. ABNT NBR 7211. Agregados Para Concreto-Especificação; Brazilian Association of Technical Standards: São Paulo, Brazil, 2009; p. 9.

31. Jensen, O.M. Water absorption of superabsorbent polymers in a cementitious environment. In International RILEM Conference On Advances in Construction Materials Through Science and Engineering; RILEM Publications SARL: Hong Kong, China, 2011; pp. 22-35.

32. Snoeck, D.; Velasco, L.F.; Mignon, A.; Van Vlierberghe, S.; Dubruel, P.; Lodewyckx, P.; De Belie, N. The effects of superabsorbent polymers on the microstructure of cementitious materials studied by means of sorption experiments. Cem. Concr. Res. 2015, 77, 26-35. [CrossRef]

33. De Rooij, M.; Van Tittelboom, K.; De Belie, N.; Schlangen, E. RILEM TC 221-SHC: Self-Healing Phenomena in Cement-Based Materials; Springer Science \& Business Media: Berlim, Germany, 2013; Volume 1.

34. DIN 18555-2 Testing of Mortars Containing Mineral Binders_Freshly Mixed Mortars Containing Aggregates of Dense Structure (Heavy Aggregates)_Determination of Consistence, Bulk Density and Air Content; DIN/EN: Berlin, Germany, 1982.

35. ABNT NBR 5739. Concrete-Compression Test of Cylindrical Specimens; Brazilian Association of Technical Standards: São Paulo, Brazil, 2018; p. 71. 
36. Silva, E.F. Variações Dimensionais em Concretos de alto Desempenho Contendo Aditivo Redutor de Retração. Ph.D. Thesis, Universidade do Rio de Janeiro, Rio de Janeiro, Brazil, 2007.

37. Tawaza, E. Autogenous Shrinkage of Concrete, 1st ed.; CRC Press: London, UK, 1999.

38. ASTM C490 Standard Practice for Use of Apparatus for the Determination of Length Change of Hardened Cement Paste, Mortar, and Concrete; ASTM Standard: West Conshohocken, PA, USA, 2000.

39. Yokota, H.; Rokugo, K.; Sakata, N. JSCE Recommendations for Design and Construction of High Performance Fiber Reinforced Cement Composite with Multiple Fine Cracks. In High Performance Fiber Reinforced Cement Composites; Springer: Tokyo, Japan, 2008.

40. Schreier, H.; Orteu, J.J.; Sutton, M.A. Image Correlation for Shape, Motion and Deformation Measurements: Basic Concepts, Theory and Applications; Springer: Berlin, Germany, 2009.

41. BS EN 12390-6. Testing Hardened Concrete. Tensile Splitting Strength of Test Specimens; British Standard Institution: London, UK, 2009; p. 14.

42. Paiva, H.; Esteves, L.; Cachim, P.; Ferreira, V.F. Rheology and hardened properties of single-coat render mortars with different types of water retaining agents. Constr. Build. Mater. 2009, 1141-1146. [CrossRef]

43. Bayasi, M.Z.; Soroushian, P. Effect of steel fiber reinforcement on fresh mix properties of concrete. ACI Mater. J. 1992, 89, 369-374.

44. Ferrara, L.; Meda, A. Relationships between fibre distribution, workability and the mechanical properties of SFRC applied to precast roof elements. Mater. Struct. Constr. 2006, 39, 411-420. [CrossRef]

45. Holschemacher, K.; Mueller, T.; Ribakov, Y. Effect of steel fibres on mechanical properties of high-strength concrete. Mater. Des. 2010, 31, 2604-2615. [CrossRef]

46. Filho, R.D.T.; Silva, E.F.; Lopes, A.N.M.; Mechtcherine, V.; Dudziak, L. Effect of superabsorbent polymers on the workability of concrete and mortar. In Application of Super Absorbent Polymers (SAP) in Concrete Construction: State-of-the-Art Report Prepared by Technical Committee 225-SAP; Springer: Berlin, Germany, 2012; pp. 39-50.

47. Liu, J.; Khayat, K.H.; Shi, C. Effect of superabsorbent polymer characteristics on rheology of ultra-high performance concrete. Cem. Concr. Compos. 2020, 112, 103636. [CrossRef]

48. Faping, L.; Jiesheng, L. Study on the Properties and Mechanism of Mortars Modified by Super Absorbent Polymers. J. Test. Eval. 2019, 47, 20170374. [CrossRef]

49. Dudziak, L.; Mechtcherine, V. Mitigation of volume changes of ultra-high performance concrete (UHPC) by using super absorbent polymers. In Proceedings of the 2nd International Symposium on Ultra High Performance Concrete, Kassel, Germany, 5-7 March 2008; pp. 425-432.

50. Zhao, S.; Jensen, O.M.; Hasholt, M.T. Measuring absorption of superabsorbent polymers in cementitious environments. Mater. Struct. Constr. 2020, 53, 1-16. [CrossRef]

51. Snoeck, D.; Schaubroeck, D.; Dubruel, P.; De Belie, N. Effect of high amounts of superabsorbent polymers and additional water on the workability, microstructure and strength of mortars with a water-to-cement ratio of 0.50. Constr. Build. Mater. 2014, 72, 148-157. [CrossRef]

52. Chindasiriphan, P.; Yokota, H.; Pimpakan, P. Effect of fly ash and superabsorbent polymer on concrete self-healing ability. Constr. Build. Mater. 2020, 233, 116975. [CrossRef]

53. Lee, H.X.D.; Wong, H.S.; Buenfeld, N.R. Self-sealing of cracks in concrete using superabsorbent polymers. Cem. Concr. Res. 2016, 79, 194-208. [CrossRef]

54. ACI Committee 363. 363R-10 Report on High-Strength Concrete; ACI Mater. J.: Farmington Hills, MI, USA, 2010.

55. Concreto Para Fins Estruturais-Classificação pela Massa Específica, por Grupos de Resistência e Consistência; Assoc. Bras. Normas Técnicas: São Paulo, Brazil, 2015; ABNT NBR 8953:2015.

56. Lura, P.; Jensen, O.M.; Van Breugel, K. Autogenous shrinkage in high-performance cement paste: An evaluation of basic mechanisms. Cem. Concr. Res. 2003, 33, 223-232. [CrossRef]

57. Wyrzykowski, M.; Terrasi, G.; Lura, P. Expansive high-performance concrete for chemical-prestress applications. Cem. Concr. Res. 2018, 107, 275-283. [CrossRef]

58. Aveston, J.; Kelly, A. Theory of multiple fracture of fibrous composites. J. Mater. Sci. 1973, 8, 352-362. [CrossRef]

59. Gray, R.J. Analysis of the effect of embedded fibre length on fibre debonding and pull-out from an elastic matrix-Part 1 Review of theories. J. Mater. Sci. 1984, 19, 861-870. [CrossRef]

60. Rossi, P.; Richer, S. Numerical modelling of concrete cracking based on a stochastic approach. Mater. Struct. 1987, 20, 334-337. [CrossRef] 
61. Rasheed, M.A.; Prakash, S.S. Behavior of hybrid-synthetic fiber reinforced cellular lightweight concrete under uniaxial tension-Experimental and analytical studies. Constr. Build. Mater. 2018, 162, 857-870. [CrossRef]

62. Voo, J.Y.L.; Foster, S. Tensile-fracture of fibre-reinforced concrete: Variable engagement mode. In 6th International RILEM Symposium on Fibre Reinforced Concretes; RILEM Publications SARL: Varenna, Italy, 2004; pp. 875-884.

63. Lei, Y.; Dura, V.; Sdn, T.; Foster, S.; Sydney, U.; Voo, Y.L. Variable Engagement Model for the Design of Fibre Reinforced Concrete Structures. In Proceedings of the Advanced Materials for Construction of Bridges, Buildings, and Other Structures III, Davos, Switzerland, 7-12 September 2005.

64. Orange, G.; Acker, P.; Vernet, C. A new generation of UHP Concrete: Ductal damage resistance and micromechanical analysis. In Proceedings of the Fifth RILEM Symp. Fiber-Reinforced Concr., Lyon, France, 13-15 September 2000.

Publisher's Note: MDPI stays neutral with regard to jurisdictional claims in published maps and institutional affiliations.

(C) 2020 by the authors. Licensee MDPI, Basel, Switzerland. This article is an open access article distributed under the terms and conditions of the Creative Commons Attribution (CC BY) license (http://creativecommons.org/licenses/by/4.0/). 